\title{
PENDIDIKAN KESEHATAN TENTANG PENCEGAHAN COVID 19 DI DESA CILEMBU KECAMATAN PAMULIHAN KABUPATEN SUMEDANG
}

\author{
Udin Rosidin, Desy Indra Yani, Mamat Lukman dan Adelse Prima Mulya \\ Fakultas Keperawatan, Universitas Padjadjaran \\ E-mail: udin.rosidin@unpad.ac.id
}

\begin{abstract}
ABSTRAK. Kegiatan ini dilatarbelakangi oleh pandemi Covid 19 yang terus meningkat. Untuk mengatasi masalah tersebut diperlukan upaya pencegahan covid 19 oleh seluruh masyarakat termasuk masyarakat Desa Cilembu Sumedang. Dalam survey awal menunjukkan masih banyak masyarakat yang tidak melaksanakan protokol kesehatan. Masih ada masyarakat yang beranggapan bahwa Covid 19 adalah tidak nyata. Memakai masker karena takut razia. Sebagian masih tetap bekerja diluar rumah. Padahal untuk pencegahan covid 19 harus dilaksanakan oleh seluruh masyarakat. Melihat kondisi tersebut diperlukan adanya pendidikan kesehatan tentang covid 19 kepada masyarakat Desa Cilembu. Tujuan kegiatan adalah untuk meningkatkan pengetahuan masyarakat Desa Cilembu dalam pencegahan covid 19. Metode kegiatan yang dilaksanakan mulai dari persiapan sosial kemudian pelaksanaan penyuluhan dilaksanakan secara online melalui aplikasi whatsapp dan zoom. Analisis data dilakukan dengan uji paired samples T test. Hasil kegiatan menunjukan sebelum dilakukan pendidikan kesehaan rata rata nilai pengetahuan sebesar 76,87 dan setelah dilakukan meningkat menjadi 83,75 point dengan nilai $p$ sebesar 0,001 . Peningkatan pengetahuan tersebut merupakan awal yang baik untuk melaksanakan protokol kesehatan. Diharapkan masyarakat yang mengikuti kegiatan ini bisa mensosialisasikan kepada masyarakat sekitarnya sehingga upaya pencegahan covid 19 dilaksanakan oleh seluruh masyarakat Desa Cilembu. Kesimpulan kegiatan ini adalah adanya peningkatan pengetahuan masyarakat tentang pencegahan covid 19 setelah dilakukan pendidikan kesehatan. Agar peningkatan pengetahuan tersebut menjadi perilaku pencegahan covid 19 maka sangat diperlukan upaya tindak lanjut pembinaan dari penanggung jawab wilayah.
\end{abstract}

Kata kunci: Pendidikan kesehatan; Pencegahan Covid 19; Peningkatan Pengetahuan.

ABSTRACT. This activity is motivated by the COVID-19 pandemic which continues to increase. To overcome this problem, efforts to prevent Covid 19 are needed by the entire community including the people of Cilembu Sumedang Village. Initial surveys show that there are still many people who do not implement health protocols. There are still people who think that Covid 19 is not real. Wear a mask for fear of raids. Some are still working outside the home. Even though the prevention of Covid 19 must be carried out by the entire community. Seeing these conditions, it is necessary to have health education about covid 19 for the people of Cilembu Village. The purpose of the activity is to increase the knowledge of the people of Cilembu Village in the prevention of covid 19. The method of activities carried out starts from social preparation to the implementation of counseling carried out online through the WhatsApp application and zoom. Data analysis was performed by using paired samples T test. The results of the activity showed that before health education was carried out the average value of knowledge was 76.87 and after it was carried out it increased to 83.75 points with a p-value of 0.001 . This increase in knowledge is a good starting point for implementing health protocols. It is hoped that people who take part in this activity can disseminate information to the surrounding community so that efforts to prevent COVID-19 are carried out by all Cilembu Village residents. The conclusion of this activity is that there is an increase in public knowledge about preventing covid 19 after health education is carried out. In order for this increase in knowledge to become Covid 19 prevention behavior, it is necessary to follow up the efforts of guidance from the person in charge of the area.

Keywords: Health education; Covid 19 Prevention; Knowledge Enhancement.

\section{PENDAHULUAN}

Kondisi dunia saat ini sedang dilanda pandemi covid 19. Di beberapa negara termasuk Indonesia kasus covid 19 terus meningkat. Di Indonesia penambahan jumlah kasus terkonfirmasi pada bulan Mei 2020 masih berada pada angka 10.552 kasus dengan 800 orang meninggal dunia, akan tetapi hingga Juni 2020 kasus bertambah menjadi 40.400 kasus dengan jumlah kematian sebanyak 2.231 (Purnamasari \& Raharyani, 2020). Provinsi Jawa Barat merupakan provinsi terbanyak kedua setelah DKI Jakarta dengan total kasus 193 ribu. Kabupaten Sumedang sampai tanggal 27 Mei 2020, terkonfirmnasi 12 orang positif 3 orang sembuh dan 9 orang masih dalam perawatan. Kabupaten Sumedang yang merupakan salah satu kabupaten yang masuk dalam PSBB Bandung Raya (Wibowo \& Afriyani, 2021). Coronavirus Disease 2019 (Covid-19) adalah penyakit jenis baru yang belum pernah diidentifikasi sebelumnya pada manusia (Wulandari et al., 2020). Kondisi tersebut seharusnya menjadi acuan atau perhatian supaya masyarakat dapat meningkatkan perilaku hidup bersih dan sehat serta mematuhi protokol kesehatan yang sudah ditentukan pemerintah.

Perilaku hidup bersih dan sehat yang sudah dicanangkan pemerintah melalui gerakan masyarakat sehat adalah salah satu upaya untuk memberdayakan masyarakat dalam mencegah berbagai penyakit 
infeksi maupun penyakit degeneratif. Menurut pedoman PHBS, perilaku hidup bersih dan sehat didefinisikan sebagai perilaku proaktif untuk memelihara dan meningkatkan kesehatan, mencegah resiko terjadinya penyakit, melindungi diri dari ancaman penyakit, serta berperan aktif dalam gerakan kesehatan masyarakat (Kemenkes, 2011). Perilaku sehat tersebut dicanangkan pemerintah dalam Program Germas pada tanggal 15 November 2016. Upaya tersebut dilakukan untuk memberdayakan masyarakat dalam memelihara, meningkatkan dan melindungi kesehatannya. Sehingga masyarakat sadar, mau, dan mampu secara mandiri ikut aktif dalam meningkatkan status kesehatannya. Gerakan hidup sehat merupakan upaya yang sangat tepat dilakukan, terutama pada kondisi saat ini dimana seluruh negara sedang mengatasi masalah kesehatan dunia yaitu Pandemi Covid 19 (Rosidin, Rahayuwati, $\&$ Herawati, 2020).

Pencegahan Covid 19 harus dilakukan oleh seluruh masyarakat. Maka kewaspadaan kesehatan masyarakat harus diterapkan. Masyarakat harus disiplin dan tidak lelah dalam melaksanakan protokol kesehatan sebagai upaya promotif dan preventif pencegahan covid 19. Masyarakat harus meyakini bahwa covid 19 benar benar nyata dan mengancam seluruh penduduk dunia. Tindakan pencegahan merupakan kunci penerapan di masyarakat. Langkah langkah pencegahan yang paling efektif di masyarakat meliputi 1) melakukan kebersihan tangan menggunakan hand sanitizer jika tangan tidak terlihat kotor atau cuci tangan dengan sabun jika tangan terlihat kotor, 2) menghindari menyentuh mata, hidung, dan mulut, 3) terapkan etika batuk atau bersin dengan menutup hidung dan mulut dengan lengan atas bagian dalam atau tisu, lalu buanglah tisu ketempat sampah, 4) pakailah masker medis jika memiliki gejala pernapasan dan melakukan kebersihan tangan setelah membuang masker dan 5) menjaga jarak (minimal 1 meter) dari orang mengalami gejala gangguan pernapasan (Kemenkes, 2020). Upaya pencegahan tersebut merupakan sebuah perilaku kesehatan yang harus dilaksanakan oleh seluruh masyarakat.

Dalam upaya menggali perilaku hidup sehat dimasyarakat, mahasiswa Profesi Ners angkatan 39 Fakultas Keperawatan Universitas Padjadjaran melaksanakan survey di Desa Cilembu Kecamatan Pamulihan Kabupaten Sumedang. Dalam survey tersebut mahasiswa juga merangkap sebagai petugas satgas AMARI Covid-19. Survey tersebut merupakan langkah awal untuk menggali keadaan dan masalah yang dihadapi masyarakat serta potensipotensi yang dimiliki masyarakat dalam mengatasi masalah kesehatan baik kondisi kesehatan warga maupun upaya pencegahan penyakit khususnya covid-19. Dalam survey awal tersebut ditemukan masih banyak masyarakat yang tidak melaksanakan protokol kesehatan. Berdasarkan hasil wawancara dengan bidan desa yang bertugas di Desa Cilembu menyebutkan bahwa selama new normal warga Desa Cilembu kurang disiplin dalam menerapkan protokol kesehatan, seperti jarang menggunakan masker dan tidak menjaga jarak. Kalaupun memakai masker karena takut razia, serta masih banyak masyarakat yang bekerja di luar rumah Selain itu dalam survey tersebut mendapatkan beberapa data tentang pengetahuan, sikap dan perilaku masyarakat dalam pencegahan covid 19.

Memperhatikan hasil survey tersebut mahasiswa dan dosen pembimbing lapangan berpendapat masih sangat dibutuhkan berbagai intervensi untuk meningkatkan pengetahuan sikap dan perilaku masyarakat Desa Cilembu dalam pencegahan covid 19. Perilaku pencegahan covid 19 harus seratus persen dilaksanakan oleh masyarakat. Berdasarkan permasalahan tersebut diatas kemudian tim mengadakan pertemuan dengan para tokoh masyarakat dan sepakat mengadakan musyawarah masyarakat desa untuk membahas hasil survey dan mencari kesepakatan untuk menyelesaikan permasalahan tersebut. Musyawarah masyarakat Desa Cilembu dilaksanakan pada tanggal 14 September 2020 dengan menggunakan media Google Meet yang dihadiri kepala Puskesmas Haurngombong, Kepala Desa Cilembu, para ketua RT dan RW, serta warga dan kader kesehatan. Peserta musyawarah tersebut sepakat akan melakukan dan mendukung kegiatan untuk mengatasi masalahmasalah yang ditemukan terutama dalam pencegahan covid 19.

Target yang diharapkan dari kegiatan pengabdian pada masyarakat ini yaitu adanya peningkatan pengetahuan masyarakat tentang pencegahan covid 19. Dengan pengetahuan yang baik tersebut akan berdampak baik pula kepada sikap dan perilaku masyarakat dalam pencegahan covid 19. Perilaku masyarakat untuk membiasakan melaksanakan protokol kesehatan sebagai upaya pencegahan terhadap covid 19 harus diawali dengan pengetahuan yang baik (Kaidah, Budiarti, Yasmina, \& Heriyani, 2020). Perubahan perilaku masyarakat akan terjadi apabila masyarakat memiliki pengetahuan, pemahaman dan sikap yang baik tentang pencegahan covid 19. Pencegahan covid 19 adalah sebuah perilaku yang harus didukung oleh pengetahuan yang cukup dan sikap yang positif terhadap upaya pencegahan covid 19. Karena perilaku kesehatan yang diharapkan harus berdasarkan keinginannya sendiri tanpa paksaan orang lain maka upaya peningkatan pengetahuan dan sikap harus benarbenar mendukung perilaku tersebut. Melaksanakan 
perilaku sehat tanpa paksaan harus memperhatikan tiga domain perilaku ; Pengetahuan (knowledge), Sikap (attitude) dan Tindakan (practice). Melalui domain tersebut maka perilaku kesehatan dapat dilaksanakan dengan kesadarannya sendiri (Notoatmodjo, 2014).

Berdasarkan latar belakang diatas, tim pengabdiaan mengidentifikasi perlunya beberapa kegiatan tentang pencegahan covid 19. Masyarakat Desa Cilembu memerlukan adanya informasi tentang pentingnya pencegahan covid 19. Masyarakat pada umumnya beranggapan bahwa covid 19 tidak nyata, menggunakan masker karena takut razia dan selalu mengabaikan protokol kesehatan lainnya. Memperhatikan hal tersebut sangat perlu dilakukan adanya pendidikan kesehatan tentang covid 19 pada masyarakat Desa Cilembu. Dengan pemahaman yang benar tentang covid 19 maka masyarakat akan melaksanakan upaya pencegahan dengan kesadarannya sendiri. Sehingga diharapkan setelah dilakukan kegiatan pengabdian ini masyarakat Desa Cilembu memiliki pengetahuan, sikap dan perilaku yang baik tentang pencegahan covid 19 .

\section{METODE}

Sesuai dengan kesepakatan antara Tim mata ajaran keperawatan komunitas Fakultas Keperawatan Universitas Padjadjaran dengan kepala Puskesmas Haurngombong bahwa Kecamatan Pamulihan dijadikan daerah binaan mahasiswa Profesi Ners angkatan 39. Sebelum kegiatan PPM dilaksanakan Tim PPM terlebih dahulu mengadakan pertemuan dengan Kepala Puskesmas Haurngombong dan Kepala Desa Cilembu. Kemudian mahasiswa melakukan survey untuk mengetahui permasalahan kesehatan yang sedang terjadi. Permasalahan yang ditemukan pada survey tersebut kemudian dibahas dalam musyawarah masyarakat desa. Musyawarah menyepakati adanya kegiatan pengabdian pada masyarakat untuk mengatasi permasalahan yang ditemukan yaitu pendidikan kesehatan tentang pencegahan covid 19. Kegiatan pengabdian diawali dengan persiapan sosial yang bertujuan untuk membangun komitmen dari semua pihak yang terkait seperti Kepala Puskesmas Haurngombong, Kepala Desa Cilembu, Ketua RT/RW dan kader kesehatan. Setelah program disepakati maka dilaksanakan kegiatan pendidikan kesehatan tentang pencagahan covid 19 kepada masyarakat. Pendidikan kesehatan dilaksanakan pada hari Jumat tanggal 2 Oktober 2020 jan 13.00 sampai dengan jam 15.30 WIB. Kegiatan pendidikan kesehatan dilaksanakan secara online melalui aplikasi whatsapp dan zoom. Media pendidikan kesehatan yang digunakan adalah poster, power point, dan vidio. Peserta kegiatan adalah masyarakat yang memiliki fasilitas untuk akses terhadap aplikasi zoom berjumlah 16 orang. Sebelum dilakukan pendidikan kesehatan terlebih dahulu dilakukan pretest dan setelah dilakukan pendidikan kesehatan dilakukan posttest sebagai bahan evaluasi kegiatan. Pengetahuan masyarakat Desa Cilembu dalam pencegahan covid 19 diukur dengan pertanyaan melalui gform. Dalam pelaksanaan pengabdian kepada masyarakat dilakukan beberapa strategi yang dilaksanakan diantaranya ; a) mensosialisasikan kegiatan pendidikan kesehatan kepada masyarakat dan tokoh masyarakat di Desa Cilembu; b) mempersiapkan kegiatan pendidikan kesehatan tentang pencegahan covid 19 dan pengembangan media yang sesuai ; c) melaksanakan kegiatan pendidikan kesehatan tentang covid 19 yang dilakukan secara daring dan d) melaksanakan evaluasi terhadap kegiatan pendidikan kesehatan yang sudah dilaksanakan. Analisis data dilakukan dengan uji statistik. Kegiatan akhir dari PPM ini adalah melakukan evaluasi dengan cara membandingkan rata-rata nilai pengetahuan, standart deviasi, nilai minimum, nilai maksimum sebelum dan sesudah pelaksanaan pendidikan kesehatan kemudian dilakukan uji statistik dengan menggunakan paired samples $T$ test. Setelah kegiatan pendidikan kesehatan dilaksanakan, kemudian dibuat dokumen dan melaporkan hasil kegiatan kepada Kepala Desa Cilembu dan Kepala Puskesmas Haurngombong.

\section{HASIL DAN PEMBAHASAN}

Hasil kegiatan pengabdian masyarakat difokuskan pada upaya peningkatan pengetahuan masyarakat tentang pencegahan covid 19. Hasil kegiatan menunjukkan bahwa pengetahuan masyarakat tentang covid 19 didapatkan hasil rata rata menjawab benar pada setiap soal sebanyak $68,2 \%$ sedangkan menjawab salah sebanyak 31,8 $\%$. Hasil pretest menunjukkan bahwa rata rata nilai pengetahuan tentang pencegahan covid 19 adalah sebesar 76,87 dan setelah dilakukan pendidikan kesehatan meningkat menjadi 83,75 point. Hasil selengkapnya dapat dilihat dalam tabel berikut :

Tabel 1. Hasil Kegiatan Pendidikan Kesehatan Tentang Pencegahan Covid 19 Di Desa Cilembu Kecamatan Pamulihan Sumedang

\begin{tabular}{lccccc}
\hline Pengetahuan & Mean & SD & Minimum & Maksimum & $\begin{array}{c}\mathrm{P} \\
\text { Value }\end{array}$ \\
\hline Pretest & 76.87 & 14,0 & 50 & 100 & 0,001 \\
Postest & 83,75 & 10,8 & 70 & 100 & \\
\hline
\end{tabular}

Memperhatikan tabel tersebut dapat dilihat bahwa kegiatan pendidikan kesehatan yang dilaksanakan dapat meningkatkan rata rata nilai 
pengetahuan sebesar 6,88 point. Nilai minimum semakin naik dari 50 menjadi 70 point. Demikian juga dengan standart deviasi, penyebaran data sebelum pendidikan kesehatan sebesar 14,0 dan setelah dilaksanakan pendidikan kesehatan menjadi lebih terfokus dan mengecil menjadi 10,8. Hasil uji statistik menunjukkan nilai $\mathrm{p}$ sebesar 0,001 maka dapat disimpulkan ada perbedaan yang signifikan antara rata-rata nilai pengetahuan sebelum dan sesudah pelaksanaan pendidikan kesehatan. Hasil kegiatan pengabdian ini memperlihatkan adanya peningkatan pengetahuan masyarakat tentang pencegahan Covid 19. Hal ini sesuai dengan kegiatan sebelumnya bahwa ada pengaruh pelaksanaan pendidikan kesehatan terhadap peningkatan pengetahuan (Rosidin, Sumarna, Eriyani, \& Noor, 2021). Peningkatan rata rata nilai tersebut merupakan modal bagi para peserta pendidikan kesehatan dalam melakukan kegiatan lanjutan seperti; a) mensosialisakan kepada masyarakat tentang pandemi covid 19 sehingga masyarakat akan memiliki pemahaman yang benar tentang pandemi covid 19; b) membimbing masyarakat agar bisa melaksanakan pencegahan covid 19 secara mandiri seperti menggunakan masker dengan benar, mencuci tangan sesuai dengan langkah langkah yang benar, selalu menjaga jarak dan selalu menghindari kerumunan dengan didasari oleh pemahaman yang benar dan c) meminta masyarakat agar selalu mengingatkan keluarga, tetangga dan anggota masyarakat lainnya untuk tidak lalai dalam melakukan pencegahan covid 19.

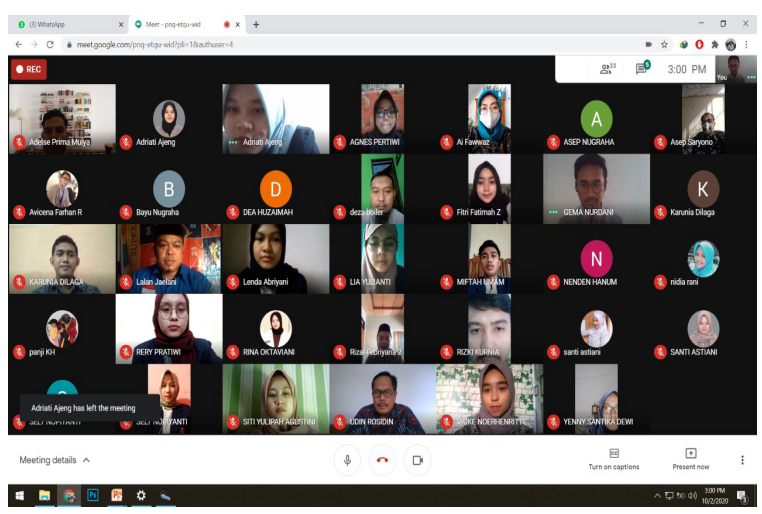

Gambar 1. Persiapan Sosial bersama Kepala Desa Cilembu, Dosen pembimbing dan mahasiswa

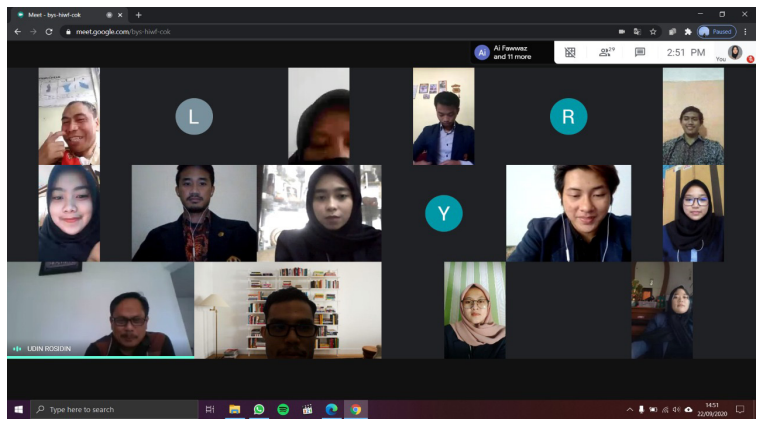

Gambar 2. Kegiatan Pendidikan Kesehatan yang dilaksanakan secara daring
Peningkatan pengetahuan melalui kegiatan pendidikan kesehatan sangat dimungkinkan selama kegiatan tersebut dilaksanakan dengan menggunakan media yang tepat, menarik dan mudah dipahami. Dalam kegiatan pendidikan kesehatan tim pengabdian menggunakan media penyuluhan berupa poster, power point dan video. Penyediaan media serta metodologi pendidikan yang dinamis serta dialogis sangat diperlukan bagi pengembangan potensi peserta didik secara optimal. Hal ini disebabkan karena potensi peserta didik akan lebih terangsang bila dibantu dengan sejumlah media atau sarana dan prasarana yang mendukung proses interaksi yang sedang dilaksanakan (Arsyad, 2011). Penggunaan media dalam pendidikaan kesehatan secara daring akan berpengaruh terhadap peningkatan pengetahuan peserta. Oleh karena itu materi tentang pencegahan covid 19 yang akan disampaikan dikemas terlebih dahulu dalam media yang tepat seperti dalam format video dan audio. Peningkatan pengetahuan terjadi secara signifikan setelah diberikan video. Hal ini dikarenakan video sangat menarik baik tampilan maupun suara, mudah dipahami, dan tidak membosankan. Selain itu, video dapat menyajikan informasi berupa animasi dan memaparkan proses terjadinya penyakit dengan lebih mudah (Zulfa \& Kusuma, 2020).

Selain penggunaan media yang tepat, bentuk informasiyang disampaikan jugaakanmempengaruhi peningkatan pengetahuan peserta kegiatan. Kegiatan pendidikan kesehatan yang dilaksanakan terhadap masyarakat Desa Cilembu disajikan dalam bentuk informasi yang mudah untuk dipahami. Informasi yang disajikan dalam bentuk media video dan audio tersebut menarik perhatian masyarakat yang mengikuti kegiatan pendidikan kesehatan. Informasi yang diberikan selain penyuluhan langsung, peserta juga menggunakan media whatsapp group untuk diskusi dan tanya jawab. Melalui media ini peserta dapat bertanya secara langsung kepada narasumber tanpa harus mengganggu kegiatan penyuluhan. Penyebaran informasi yang tepat dapat meningkatkan pengetahuan seseorang (Sumarni, Rosidin, \& Sumarna, 2020).

Masyarakat Desa Cilembu yang mengikuti kegiatan pendidikan kesehatan ini merasa yakin dan percaya diri dengan peningkatan pengetahuan yang dialaminya. Mereka merasakan sudah menjadi bagian dari tim pengabdian yang akan memberikan informasi lanjutan kepada masyarakat. Masyarakat yang mengikuti pendidikan kesehatan memiliki motivasi yang baik dan berkomitmen bersama mahasiswa Profesi Ners 39 untuk mensosialisasikan protokol kesehatan kepada masyarakat Desa Cilembu yang tidak dapat mengikuti pendidikan kesehatan dalam pencegahan covid 19. Sehingga ilmu yan 
didapat dalam kegiatan ini juga akan bermanfaat bagi warga sekitarnya. Pendidikan kesehatan dapat menumbuhkan dan meningkatkan motivasi untuk melaksanakan apa yang diberikan dalam kegiatan tersebut (Budiana, Sjafirah, \& Bakti, 2015)

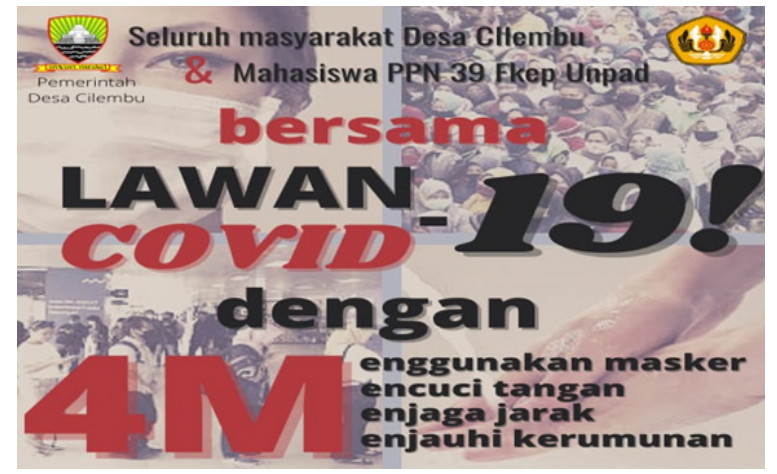

Gambar 3. Peserta Pendidikan kesehatan berkomitmen untuk melawan covid 19

Niat baik dari peserta tersebut harus didukung oleh semua pihak. Peserta yang sebagian besar tokoh masyarakat dapat menjadi potensi untuk menindak lanjuti kegiatan pencegahan covid 19. Sehingga seluruh masyarakat dapat berpartisipasi dalam upaya memutus mata rantai penularan covid 19. Tokoh masyarakat adalah panutan warganya, sehingga apapun yang akan disarankan tokoh masyarakat akan diikuti oleh warganya. Kedekatan tokoh masyarakat dengan masyarakat dapat mempermudah para tokoh untuk melibatkan masyarakat dalam berbagai kegiatan (Darwis \& Zulfan, 2018). Kegiatan pendidikan kesehatan melalui google meet dan whatsapp group berjalan dengan lancar dan sesuai dengan waktu yang direncanakan, peserta memperhatikan materi pendidikan kesehatan yang diberikan, peserta pendidikan kesehatan aktifbertanya pada sesi tanya jawab. Rencana tindak lanjut yang akan kami lakukan koordinasi dengan kepala desa, bidan desa, pihak puskesmas dan tokoh masyarakat desa Cilembu untuk memantau masyarakat agar tetap menerapkan protokol kesehatan covid-19 di lingkungan Desa Cilembu.

Kegiatan pengabdian yang dilakukan dapat terimplementasi sesuai dengan rencana dan berjalan dengan lancar, karena dengan adanya koordinasi yang baik antara mahasiswa dengan pihak Desa Cilembu. Tim pengabdian juga melakukan koordinasi dengan kepala Puskesmas Haurngombong dan kader kesehatan terkait adanya 8 orang warga yang mengalami gangguan kesehatan. Serta dipastikan warga yang mengalami gangguan kesehatan tersebut mendapatkan pelayanan kesehatan di puskesmas dengan baik. Tim juga melakukan koordinasi dengan pemerintah Desa Cilembu, para ketua RT dan RW untuk selalu memantau dan mengingatkan masyarakat agar selalu menerapkan protokol kesehatan covid-19 di lingkungan Desa Cilembu.

\section{SIMPULAN}

Pendidikan Kesehatan tentang covid 19 pada masyarakat Desa Cilembu berjalan dengan lancar. Uji statistik menunjukkan adanya peningkatan pengetahuan msyarakat tentang pencegahan covid 19 setelah dilakukan pendidikan kesehatan. Dengan adanya peningkatan pengetahuan tersebut, diharapkan kesadaran masyarakat meningkat terhadap pencegahan covid 19. Kegiatan yang sudah dilaksanakan diharapkan dapat berkelanjutan secara mandiri oleh masyarakat Desa Cilembu Kecamatan Pamulihan Kabupaten Sumedang. Pihak terkait seperti Puskesmas Haurngombong diharapkan dapat melakukan pembinaan secara intensif kepada masyarakat sehingga perilaku yang sudah baik dapat dipertahankan. Kemandirian masyarakat terhadap pencegahan covid 19 harus terus digalakan, tidak boleh lengah dan terus melakukan pendampingan kepada masyarakat.

\section{UCAPAN TERIMA KASIH}

Kegiatan pengabdian ini yang berjudul Pendidikan kesehatan tentang pencegahan covid 19 pada masyarakat Desa Cilembu Kabupaten Sumedang dapat berjalan dengan baik atas dukungan dari berbagai pihak. Oleh karena itu penulis ingin mengucapkan terimakasih yang sebesar-besarnya kepada: Rektor Universitas Padjadjaran, Dekan Fakultas Keperawatan Unpad, Kepala Puskesmas Haurngombong, Kepala Desa Cilembu, Mahasiswa PPN 39 dan seluruh pihak yang penulis tidak bisa sebutkan satu persatu. Akhir kata penulis ucapkan, semoga kebaikan yang dilakukan oleh pihak-pihak diatas dibalas oleh Allah SWT, Aamiin

\section{DAFTAR PUSTAKA}

Arsyad, A. (2011). Media pembelajaran. Jakarta: PT Raja grafindo persada.

Budiana, H. R., Sjafirah, N. A., \& Bakti, I. (2015). Pemanfaatan Teknologi Informasi Dan Komunikasi Dalam Pembelajaran Bagi Para Guru SMPN 2 Kawali Desa Citeureup Kabupaten Ciamis. Dharmakarya, 4(1).

Darwis, R. S., \& Zulfan, I. (2018). Peningkatan Kapasitas Tokoh Masyarakat Dalam Perencanaan Partisipatif Pembangunan Desa Kondangjajar, Kecamatan Cijulang, Kabupaten Pangandaran. Dharmakarya, 7(4), 290-297.

Kaidah, S., Budiarti, L. Y., Yasmina, A., \& Heriyani, F. (2020). Edukasi Penggunaan Masker Dan Handsanitizer Bagi Petugas 
Kebersihan Di Fakultas Kedokteran ULM. Prosiding Konferensi Nasional Pengabdian Kepada Masyarakat Dan Corporate Social Responsibility (PKM-CSR), 3, 299-306.

Kemenkes. (2020). Pedoman Pencegahan dan Pengendalian Covid 19.

Kemenkes, R. I. (2011). Pedoman pembinaan perilaku hidup bersih dan sehat (PHBS). Jakarta: Kementerian Kesehatan RI.

Notoatmodjo, S. (2014). Promosi Kesehatan dan Perilkau Kesehatan. Jakarta: Rineka Cipta.

Purnamasari, I., \& Raharyani, A. E. (2020). Tingkat pengetahuan dan perilaku masyarakat Kabupaten Wonosobo tentang Covid-19. Jurnal Ilmiah Kesehatan, 10(1), 33-42.

Rosidin, U., Rahayuwati, L., \& Herawati, E. (2020). Perilaku dan Peran Tokoh Masyarakat dalam Pencegahan dan Penanggulangan Pandemi Covid-19 di Desa Jayaraga, Kabupaten Garut. Umbara, 5(1), 42-50.

Rosidin, U., Sumarna, U., Eriyani, T., \& Noor, R. M. (2021). Edukasi Daring Tentang Pencegahan Covid 19 Pada Tokoh Masyarakat Desa
Haurpanggung Kabupaten Garut. Kumawula: Jurnal Pengabdian Kepada Masyarakat, 4(1).

Sumarni, N., Rosidin, U., \& Sumarna, U. (2020). Penyuluhan Kesehatan Tentang Jajanan Sehat Di Sekolah Dasar Negeri Jati III Tarogong Kaler Garut. Kumawula: Jurnal Pengabdian Kepada Masyarakat, 3(2), 289-297.

Wibowo, M. T. H., \& Afriyani, A. (2021). Strategi Kebijakan, Tata Kelola Pemerintahan Dalam Penanganan Covid-19 Di Kabupaten Sumedang. Kebijakan: Jurnal Ilmu Administrasi, 12(1), 1-14.

Wulandari, A., Rahman, F., Pujianti, N., Sari, A. R., Laily, N., Anggraini, L., ... Azmiyannoor, M. (2020). Hubungan Karakteristik Individu dengan Pengetahuan tentang Pencegahan Coronavirus Disease 2019 pada Masyarakat di Kalimantan Selatan. Jurnal Kesehatan Masyarakat Indonesia, 15(1), 42-46.

Zulfa, F., \& Kusuma, H. (2020). Upaya Program Balai Edukasi Corona Berbasis Media Komunikasi Dalam Pencegahan Penyebaran Covid-19. Jurnal Abdimas Kesehatan Perintis, 2(1), 17-24. 